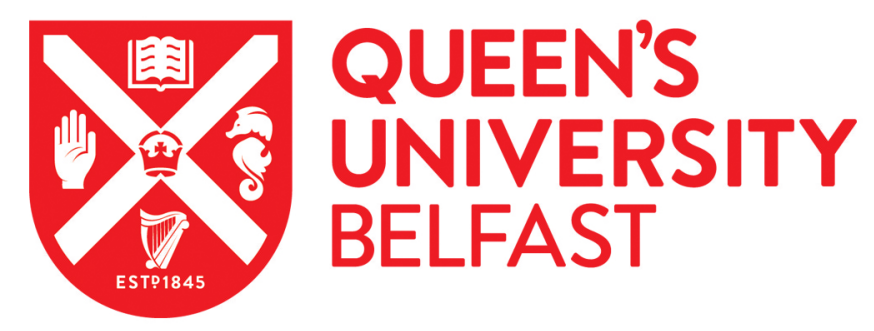

\title{
Zero Hours Contracts and Their Growth
}

Farina, E., Green, C., \& McVicar, D. (2019). Zero Hours Contracts and Their Growth. British Journal of Industrial Relations. https://doi.org/10.1111/bjir.12512

Published in:

British Journal of Industrial Relations

Document Version:

Peer reviewed version

Queen's University Belfast - Research Portal:

Link to publication record in Queen's University Belfast Research Portal

Publisher rights

Copyright 2019 Wiley. This work is made available online in accordance with the publisher's policies. Please refer to any applicable terms of use of the publisher.

\section{General rights}

Copyright for the publications made accessible via the Queen's University Belfast Research Portal is retained by the author(s) and / or other copyright owners and it is a condition of accessing these publications that users recognise and abide by the legal requirements associated with these rights.

Take down policy

The Research Portal is Queen's institutional repository that provides access to Queen's research output. Every effort has been made to ensure that content in the Research Portal does not infringe any person's rights, or applicable UK laws. If you discover content in the Research Portal that you believe breaches copyright or violates any law, please contact openaccess@qub.ac.uk. 


\title{
Zero Hours Contracts and Their Growth
}

\author{
Egidio Farina \\ Queen's University Belfast \\ e.farina@qub.ac.uk \\ Colin Green* \\ Norwegian University of Science and Technology \\ colin.green@ntnu.no \\ $\&$ \\ Duncan McVicar \\ Queen's University Belfast \& IZA \\ d.mcvicar@qub.ac.uk
}

Revised October 2019

JEL: J21, J48, M55

Keywords: zero hours contracts, no guaranteed hours contracts, casual work, precarious employment, atypical employment

\section{Acknowledgements}

This research was funded by Leverhulme Trust Research Project Grant RPG-2017-314, which we gratefully acknowledge. We also gratefully acknowledge the Office for National Statistics and the UK Data Archive for access to unit record data from multiple waves of the UK Quarterly Labour Force Survey and from multiple cohorts of the UK Longitudinal Labour Force Survey used in this paper. Thanks also to seminar participants at the 2018 Labour Force and Annual Population Surveys User Conference, London; at the 2019 Scottish Economic Society Annual Conference, Perth; at the 2019 Irish Economic Association Annual Conference, Cork; at the 2019 European Economic Association Annual Conference, Manchester; at the 2019 European Association of Labour Economists Conference, Uppsala; at the University of Stirling; at Queen's University Belfast; and to Alex Bryson, Ian Brinkley, Laura Gardiner, Stephen Clarke, Yanitsa Scott and Mark Wooden for useful comments and suggestions on earlier drafts. The findings and views reported in this paper are those of the authors and should not be attributed to the Leverhulme Trust or any of the individuals or organizations listed above.

* Corresponding author: Department of Economics, Norwegian University of Science and Technology, Klæbuveien 72, Trondheim, Norway. 


\begin{abstract}
This paper studies the prevalence and nature of zero-hours contracts (ZHCs) in the UK labour market. It is widely argued that the headline count of ZHC workers based on the Labour Force Survey historically underestimated the number of workers in ZHC jobs. Here we argue that this likely continues to be the case, particularly if one considers other, similar, no-guaranteedhours jobs alongside ZHCs. ZHC jobs and workers are heterogeneous, but ZHCs have become increasingly concentrated among young workers, full-time students, migrants, black and minority ethnic workers, in personal service and elementary occupations, and in the distribution, accommodation and restaurant sector over time. Compared to other forms of employment, median wages in ZHC jobs have also fallen. The most common prior labour market state for ZHC workers is non-ZHC employment, particularly part-time employment, with part of the reported growth in ZHCs driven by reclassification of existing employment relationships. Finally, we show that growth in public awareness of ZHCs contributed substantially to recent growth in reported ZHCs, particularly over the period 2013/14.
\end{abstract}




\section{Introduction}

There is growing concern internationally about the increasing share of contingent jobs (often described as precarious jobs) in overall employment (e.g. Katz \& Krueger, 2016; Prosser, 2016). In the UK a particular concern has been the dramatic increase in the prevalence of employment contracts that do not guarantee any hours of work at all, known as zero hours contracts (ZHCs). These types of arrangements can be attractive for employers facing erratic and unpredictable demand. They also enable employers to designate individuals as workers, with fewer entitlements and employment protection rights, rather than employees (Brinkley, 2013). ZHCs can also be attractive for workers desiring flexibility regarding when and where they work. The use of these contracts, however, raises serious questions about job insecurity, lack of access to work-related benefits and entitlements, lack of opportunity for career development, and unpredictability of hours and income, particularly if employers expect flexibility from workers but offer little flexibility in return (for evidence on this last point see CIPD, 2015). This has made them highly controversial, even as other forms of contingent employment and self-employment have also grown.

ZHCs - for which there is no universally accepted single definition - have been used in the UK and elsewhere (although they sometimes go by other names in other countries, e.g. 'If and When' contracts in Ireland (O'Sullivan et al., 2015) for many years. Adams \& Prassl (2018) suggests their use in the UK goes back to at least the 1970s, and point to examples of the use of ZHC-like contracts as far back as the $19^{\text {th }}$ Century. More recently, the Office for National Statistics (ONS) reports figures from the Quarterly Labour Force Survey (QLFS) suggesting that over 200,000 workers were employed on ZHCs in their main job in the UK in the year 2000, the earliest available data point (ONS, 2018). Their use appears to have grown rapidly over the last few years even as the labour market has tightened following the Great Recession. ONS estimates of the proportion of people in employment employed under a ZHC in their main job in the UK grew from $0.5 \%$ in 2006 to $2.8 \%$ (or 901,000 workers) in 2017 (ONS, 2018). The ONS (ONS, 2014a) notes that these statistics are likely to underestimate the actual prevalence of ZHCs because, among other things, they are based on self-reports from the QLFS and not all ZHC workers may realise they are employed under a ZHC, as opposed to, say, a casual contract (for which there is also no universally accepted single definition). Employer based surveys tend to suggest higher - possibly double - ZHC (or ZHC-like contract) prevalence (ONS, 2018), as do sectoral data (Bessa et al., 2013; Jacques, 2013; Adams \& 
Prassl, 2018). On the other hand, the QLFS may exaggerate the growth in ZHC prevalence because, as awareness of ZHCs has increased, under-reporting of ZHCs has likely decreased. Indeed the QLFS suggests that growth in the prevalence of ZHCs has levelled off since 2016. What is not in doubt is that ZHCs now constitute a significant segment of the UK labour market. They are also highly concentrated among particular demographic groups (notably young people), in particular industrial sectors (accommodation and food), and in particular occupations (caring and leisure) (ONS, 2018).

Despite this, and growing interest among researchers in the changing nature of work and contingent employment more generally, uncertainty persists about the prevalence, distribution and nature of ZHCs, and particularly about their growth over time. As a consequence, our understanding of the contemporary labour market in the UK is incomplete, and the current debate about ZHCs is taking place against the backdrop of this incomplete understanding. This paper seeks to fill these gaps in our understanding by exploiting data from the QLFS and the longitudinal LFS (LLFS). Specifically, we address the following research questions. How many workers are employed on ZHCs or ZHC-like contracts? What do ZHC jobs and workers look like? How has this changed over time? Where in (or out of) the labour market do ZHC workers come from? To what extent has the growth in reported ZHC prevalence been driven by increased awareness of ZHCs?

Our analysis suggests that the headline ZHC count from the QLFS likely continues to underestimate the number of workers whose main job is a ZHC, particularly if other noguaranteed-hours-contract (NGHC) jobs are considered alongside ZHCs. In contrast, NGHC figures reported by ONS Business Surveys (which count jobs not workers) are likely to overestimate the number of workers whose main job is a ZHC or other NGHC job. Whilst there is no perfect way to measure the number of workers on NGHCs, we argue that the two can reasonably be interpreted as lower and upper bounds on the actual number of workers in NGHCs in their main job. This puts the number of workers in the UK on a ZHC or similar NGHC in their main job somewhere between 0.9 million and 1.8 million in 2017Q4 (the latest point at which we have both QLFS and Business Survey estimates), or somewhere above 0.9 million in 2019Q2 (the latest available QLFS-based estimate). We show that ZHC workers and jobs differ in numerous characteristics compared to workers in permanent jobs. We also show that ZHCs have become increasingly concentrated at younger ages, among full-time students, among migrants, among black and minority ethnic workers, in the private sector, in personal 
service and elementary occupations, and in the distribution, accommodation and restaurant sector. Median real wages for ZHC jobs have also fallen relative to those for other jobs. The most common prior labour market state for ZHC workers is non-ZHC employment, particularly other forms of part-time employment, with part of the reported growth in ZHCs driven by reclassification of existing (within-employer) employment relationships. Finally - and this may in part explain the reclassification finding - we show that growth in public awareness of ZHCs contributed substantially to recent growth in reported ZHCs, particularly over the period 2013/14, during which it can explain between one fifth and two thirds of the growth in reported ZHCs.

\section{Existing Estimates of the Prevalence of ZHCs}

Even within the UK there is no universally accepted single definition of a ZHC (Adams \& Prassl, 2018). ZHCs have been defined by the UK government as employment contracts where the employer does not guarantee the individual any work and the individual is not obliged to accept any work offered (DBIS 2013). Evidence from the CIPD, however, suggests that ZHC workers are often expected to accept work when offered (CIPD, 2015), in which case the defining legal characteristic of a ZHC in practice is that the employer does not guarantee the ZHC worker any work. ${ }^{1}$ Dropping the no worker obligation clause, however, blurs the distinction between ZHCs and other NGHCs. In particular, casual contracts share the noguaranteed-work characteristic if they can, in practice, be severed at any time with no notice period. We are not the first to make this point (see ONS (2014b) for the UK and Lass \& Wooden (2019) internationally). Indeed, the (seemingly) preferred definition of the ONS, at least over the period 2014-2017 in its Business Surveys, omitted the no worker obligation clause and focused on NGHCs, potentially including casual contracts, more broadly (ONS, 2016). Whether seeking to measure ZHCs or NGHCs, however, the ONS and others have largely sidestepped these ambiguities by adopting survey respondents' subjective definitions of ZHCs or NGHCs. In other words, in a parallel with the debate surrounding measurement of casual employment in Australia (see Buddelmeyer \& Wooden, 2011), a worker is treated as being on a ZHC (or a NGHC) if she (or her employer) reports that they are on a ZHC (NGHC).

\footnotetext{
${ }^{1}$ This lack of mutual obligation is also a key distinction between workers and employees in UK employment law, and as workers, those employed on a ZHC generally have fewer entitlements, alongside greater precarity, compared to employees.
} 
ZHCs began to attract attention in the literature from the mid-late 1990s (e.g. Lucas, 1997), and the ONS first included a question on ZHCs in the QLFS in 2000, since which time the relevant ZHC question in the QLFS has remained broadly unchanged. Although the QLFS is a quarterly survey, information on ZHCs is collected only every other quarter, specifically in the spring and autumn quarters (up to and including 2005) or Q2 and Q4 (2006 onwards). The ONS also advise against using Q2/spring quarter data on ZHCs between 2004 and 2013 (at least naively) as survey respondents reporting that they were engaged in shift work were not allowed to answer the question on special working-hours contracts. This leads to non-trivial undercounting relative to the Q4/autumn quarter (ONS, 2014a). Consequently, ONS estimates of the number of people who are on a ZHC in their main job focus on Q4 of each year until 2013. Other sources of survey data on ZHCs (or NGHCs) with national or near-national coverage include biannual ONS Business Surveys from 2014-2017 (see ONS, 2018), ad hoc additions to Chartered Institute of Personnel and Development (CIPD) Labour Market Outlook and Employee Outlook surveys in 2013 and 2015 (see CIPD, 2013; CIPD, 2015), the 2018 LSE-CEP Survey of Alternative Work Arrangements (see Datta et al., 2018) and a question in the British Household Panel Survey (BHPS) from wave 9-18 (1999-2008) but not beyond 2008 (see Koumenta \& Williams, 2019). There are additional data available for specific sectors and occupations (see Bessa et al, 2013; Jacques, 2013). The QLFS, however, remains the most widely reported data source on ZHCs in the UK.

The ONS has published regular reports on the number and nature of ZHCs, some based entirely on the QLFS (e.g. ONS, 2017), others combining data from the QLFS and Business Survey (e.g. ONS, 2018), since 2013. Figure 1 plots the estimated number of people whose main job is a ZHC job derived from the QLFS following the ONS method, as reported in ONS (2018). Note the particularly rapid growth during 2013, continuing at a slower rate until 2016, from which point the reported number of ZHC workers has been essentially flat.

\section{INSERT FIGURE 1}

As frequently noted by the ONS (e.g. ONS, 2014a) and others (e.g. Pennycook et al., 2013), these figures are likely to underestimate the total number of people whose main job is a ZHC job, particularly earlier in the period, and therefore overestimate ZHC growth. This reflects the growing awareness of ZHCs in the media and the broader social discourse. Despite the apparent widespread acceptance of this argument no existing study has attempted to quantify the underestimation from this source or even to test the hypothesis formally. Having said that, two 
alternative descriptive avenues have been tentatively explored. First, ONS (2014a) explores the extent to which reported ZHC workers have been with their current employer for more or less than one year, concluding that at least some of the reported dramatic growth in ZHCs over 2013 comes from workers who were with their current employer in the previous year. Such reclassification of existing employment relationships could be driven by QLFS respondents relabelling their contract type despite there being no change in actual contract type, from employers moving existing workers to ZHCs from other contract types, or both. Second, CIPD (2015) and McVicar (2017) plot ZHC numbers from the QLFS alongside Google Trends data on searches for 'zero hours contracts', suggesting some co-movement, but with no formal modelling. Here we take this approach further in order to formally test (and quantify) the public awareness hypothesis.

An additional reason to suspect that the QLFS figures reported by the ONS underestimate the number of ZHCs in the period up to 2013 is that the previously mentioned shift work restriction leading to undercounting in Q2 between 2004 and 2013 is also present over this period for wave 1 respondents in Q4. ${ }^{2}$ This is acknowledged by ONS (2014a) but never acted upon in terms of publishing revised estimates. The QLFS may also undercount ZHCs (over the whole period) because the relevant question (FLEX10) is only asked of people in employment in the reference period (i.e. the previous week) which may omit some ZHC workers who worked no hours in the reference period (Adams \& Prass1, 2018). A further reason to suspect that the QLFS may underestimate the number of ZHCs (again over the whole period) is because the precise wording of the relevant question targets individuals whose working hours vary from week to week. CIPD (2015) shows that some ZHC workers work mostly regular hours and regular shifts, suggesting some of those on ZHCs in their main jobs may not respond to FLEX10 or could respond by answering 'none of the above'. Taken together, all these points suggest that QLFS estimates might plausibly be interpreted as lower bounds on the number of workers on ZHCs in their main job, even now. If so, in 2017Q4 (2019Q2), there were at least 901,000 $(896,000)$ such ZHC jobs.

The ONS began to collect information on more broadly-defined NGHCs by surveying businesses in January 2014. There have been eight further surveys spaced roughly every six months. In all cases the statistics reported from these surveys are labelled 'experimental' by

\footnotetext{
${ }^{2}$ The rolling five-wave panel structure of the LFS means that roughly one fifth of each QLFS sample is a firsttime respondent, i.e. is in wave 1 of 5 .
} 
the ONS, and this data collection exercise has now been discontinued. Nevertheless, these data are potentially informative for NGHC prevalence and in contrast to the QLFS, these Business Survey-based estimates suggest no clear trend increase over the period 2014-2017 (ONS 2018). At each point in time, however, the count is far higher than the closest QLFS estimate. The following reasons are suggested for this: (i) the Business Survey counts the number of contracts whereas the QLFS counts the number of people on a ZHC in their main job ${ }^{3}$ (some people may hold more than one job and for some NGHCs may not be the main job); (ii) employers are more likely to be aware of their workers' contractual arrangements, so are less likely to underreport NGHCs; (iii) employers are likely to interpret 'NGHCs' more broadly than ZHCs, to include other contractual arrangements without guaranteed hours (such as casual or some oncall contracts). The ONS has not yet attempted to replicate the NGHCs definition using QLFS data (or vice versa the ZHCs definition using Business Survey data), however, which makes it difficult to quantify the role of these factors. Nevertheless, for the period during which they were available, these estimates likely provide an upper bound on the number of workers specifically on a ZHC in their main job. Taken together with the QLFS estimates, the suggestion is therefore that between 0.9 million and 1.8 million workers had this contractual status in their main job in 2017Q4.

The CIPD $(2013,2015)$ reports estimates of the number of people employed on ZHCs drawing on questions included in the summer/autumn 2013 and spring/summer 2015 Labour Market Outlook surveys of employers. In summer/autumn 2013 the resulting estimate was one million, considerably higher than the nearest-in-time QLFS estimate $(585,000)$. In spring/summer 2015 the resulting estimate was 1.3 million, again considerably higher than the nearest-in-time QLFS estimate $(747,000)$. Two of the arguments set out above for why the ONS Business Survey estimates are higher than the corresponding QLFS estimates are also relevant here: (i) some workers may hold more than one job; and (ii) employers are more likely to be aware of their workers' contractual arrangements than the workers themselves. The third argument above (employers likely interpret NGHCs as a broader category than ZHCs) is not relevant in the CIPD case given the surveys refer specifically to ZHCs not NGHCs. That these CIPD estimates fall between the nearest-in-time available QLFS and ONS Business Survey estimates lends support to the lower / upper bound interpretation of these ONS estimates. Another implication is that the difference between the spring/summer 2015 CIPD estimate of the number of ZHCs

\footnotetext{
${ }^{3}$ The LFS does not ask about contractual form for second or other jobs.
} 
held by workers (1.3 million) and the nearest-in-time corresponding ONS Business Survey estimate of the number of NGHCs (1.7 million) might be interpretable as a rough estimate of the number of NGHCs that employers do not think of explicitly as ZHCs.

Moving beyond estimates based on nationally representative survey data is also potentially informative. In particular, two sectoral studies (Bessa et al., 2013; Jacques, 2013), drawing on returns from domiciliary care employers and NHS Trusts respectively, again suggest considerably higher numbers of ZHC contracts than the QLFS at the time (see also Pennycook et al., 2013; Adams \& Prass1, 2018). Using data from the National Minimum Data Set for Social Care, Bessa et al. (2013) estimate that, on average, 56\% of domiciliary care workers in England employed each year over the period 2008-12 were employed on a ZHC (although this may be an overestimate given apparently contradictory evidence on contracted hours in some cases). They cite a figure of 675,000 total workers in the sector in England in 2009, which suggests $376,000 \mathrm{ZHC}$ workers in this sector alone. Note this is prior to the rapid growth in ZHCs reported by the QLFS. Indeed, averaging over the 2008-2012 period, the QLFS suggests just $189,000 \mathrm{ZHC}$ workers (albeit in their main job) in the overall UK labour market. (Drawing on the same data source, Adams \& Prassl (2018) cite a figure of 315,000 ZHC workers in March 2016 for broadly the same sector.) Similarly (if not quite as dramatically), Jacques (2013) reports data obtained from 159 of 164 NHS Trusts in England to suggest almost 100,000 NHS workers were employed on ZHCs in early 2013, again prior to much of the growth in ZHCs reported by the QLFS. More recent ONS reports (e.g. ONS 2016) suggest around 20\% of ZHC workers, as reported by the QLFS, are to be found in the whole (1-digit) health and social work sector. This corresponds to around 50,000 in 2012, just over 100,000 in 2013, and just under 200,000 in 2016. In contrast, combining the estimates from Bessa et al. (2013) and Jacques (2013), the suggestion is that domiciliary care and the NHS - both of which are covered by but do not exhaust the one-digit health and social work sector - between them account for close to 500,000 ZHC jobs. Again, the implication is that the QLFS under-estimates the number of ZHC workers in their main job.

International comparisons of the prevalence of ZHCs or similar contracts are complicated by differences in institutions, terminology, and data collection. Some countries prevent or heavily restrict ZHCs via either regulation or collective bargaining (e.g. Germany, Netherlands); the UK is something of a permissive outlier in this respect, at least within Europe. Other labels for ZHCs or ZHC-like contracts used elsewhere include on-call (although these may also describe regular permanent contracts with an on-call element), casual, and standby contracts. Further, 
not all countries collect comparable data on ZHCs or ZHC-like contracts, although there are some exceptions (e.g. Finland collects LFS data on ZHC workers, who accounted for $4 \%$ of those in employment in 2014). For further detail on these points see O'Sullivan et al. (2015) and Datta et al. (2018). For the US, Katz and Krueger (2016) show that the proportion of those in employment who have on-call contracts grew from $1.7 \%$ in 2005 to $2.8 \%$ in 2015 . The world leader in ZHC-like employment is likely Australia, where casual workers - with contractual terms very similar to UK ZHCs - account for almost one quarter of all employees (Buddelmeyer \& Wooden, 2011).

\section{Data and Approach}

We examine QLFS data, for those aged 16+ years, over the period 2001-2018. We include proxy responses throughout and treat both the employed and self-employed as being in work. ${ }^{4}$ QLFS respondents in work are asked a specific question (FLEX10) ${ }^{5}$ on whether they work on a special working-hours contract. The structure of the question is such that respondents can choose up to three options from a list including ZHCs and on-call working (added as an option from 2010). Note that none of these options, other than ZHCs, can be unambiguously (or even predominantly) categorised as NGHCs. Also note that casual employment is not one of the options under this question. Instead, respondents are asked if they are in casual employment as part of a series of questions on whether their employment is temporary or permanent.

There are complications in using the QLFS to study the prevalence of ZHCs in the UK labour market. First, estimates of workers on ZHCs before 2006 need to be rescaled by an adjustment factor that takes into account the change from seasonal to calendar quarters. Second, the LFS data collection process is such that if respondents from one quarter are non-respondents (and no proxy response is available) in a subsequent quarter, data are carried forward from previous quarters. However, for questions not asked in the previous quarter, like the ZHC question, no data can be brought forward. In this case, the response to the question is coded as "Does Not Apply". In order to obtain an estimate of the number of ZHC workers, which takes into account these cases, we follow the ONS suggestion to assume that non-respondents are randomly

\footnotetext{
${ }^{4}$ As we might expect given the fuzzy legal boundaries here, there is some overlap between ZHC and selfemployment according to the QLFS. Over the whole period from 2001-2018, 6\% of ZHC workers also describe themselves as self-employed in their main job. This proportion has grown over time, reaching $11 \%$ in 2018 , consistent with the perceived growth of the gig economy.

${ }^{5}$ The question is worded as follows: Some people have special working hours arrangements that vary daily or weekly. In your (main) job is your agreed working arrangement any of the following...1 flexitime (flexible working hours), 2 an annualised hours contract, 3 term-time working, 4 job sharing, 5 a nine-day fortnight, 6 a four-and-a-half day week, 7 zero hours contract, 8 on-call working, or 9 none of these?
} 
distributed across contract types in proportion to respondents. Third, the Q2 (and to a lesser extent Q4) shift work check over the period 2004-2013 leads to undercounting of ZHC workers. This problem is acknowledged by the ONS but a possible solution (e.g. an adjustment factor) has not been suggested as of yet. Our own analysis of this point suggests that the Q2 check makes a small but non-trivial difference to pre-2014 second quarter estimates (see Figure 2). By undercounting ZHCs in 2012Q4 but not 2013Q4, the wave 1 check also implies that Figure 1 slightly exaggerates the growth of ZHCs over this one-year period, regardless of whether the data support the 'growing awareness' hypothesis. Fourth, as noted by Adams \& Prassl (2018), seasonal workers in Q1 or Q3, who may be disproportionately employed on ZHCs, are not counted as such given the ZHC question is asked only every other quarter.

\section{INSERT FIGURE 2}

Given the nature of the relevant questions in the LFS, broadening analysis from reported ZHCs to analysis of NGHCs more generally is not possible, although some pooling of ZHC and casual workers to this end is possible. ${ }^{6}$ Pooling workers on ZHCs with those on casual contracts who do not also report being on a ZHC adds around 200,000 workers to the estimated 0.9 million ZHC workers in recent years, e.g. in 2017Q4 we estimate between 1.08 million and 1.15 million workers to be on either casual contracts or ZHCs (depending on how one treats those casual workers who return “does not apply” for FLEX10).

To examine where in (or out of) the labour market $\mathrm{ZHC}$ workers come from, we exploit the rotating panel design of the LFS to construct a longitudinal dataset from multiple cohorts of the LLFS in which each individual is interviewed for five consecutive quarters before exiting the survey. (Note that the LLFS data made available to researchers by ONS is for the balanced panel only for each cohort, thus no explicit analysis of attrition is possible.) Specifically, we pool LLFS cohorts over the period 2001-2018 who enter the sample in Q2 or Q4, exploiting observations from the first and fifth waves in each case (i.e. observations that include the ZHC question and are one year apart). We also exploit information on the tenure of ZHC workers to explore the extent to which those entering ZHC status are doing so with the same employer (reclassification of existing employment relationships) as opposed to with a new employer.

\footnotetext{
${ }^{6}$ In particular, because the LFS does not distinguish between on-call contracts with guaranteed hours and oncall contracts without guaranteed hours, we cannot include on-call workers in estimates of NGHC workers.
} 
Finally, following a growing literature in economics focusing on how the media can influence public awareness or guide individuals' socio-economic decisions (see Carroll, 2003; Lamla \& Lein, 2008; van der Wiel, 2009; Murphy, 2017), we link the QLFS data on ZHCs described above to data on UK national newspaper articles discussing ZHCs, which we interpret as a proxy for public awareness of ZHCs. We obtain the quarterly number of UK national newspaper articles on ZHCs over the period 2001-2018, using LexisNexis, ${ }^{7}$ a full text online news and business information index. In an extension we also include local and regional newspapers to generate a regional-level version of this variable. To complement this approach we also proxy for public awareness using Google Trends data (see Edelman (2012) for a review of studies using internet data for economic research). Specifically, we obtain the quarterly number of Google searches in the UK on "zero hours contracts" over the period 2004-2018. Note that these data are only available from 2004 onwards and are reported in index form with the maximum value during the period set to 100 .

\section{The (Changing) Nature of Zero Hours Contracts}

Table 1 compares selected descriptive statistics for ZHC jobs/workers (column 1), casual workers (column 2) and those in permanent non-ZHC jobs (column 3), pooling QLFS data from 2017Q4 and 2018Q4. These estimates show marked differences between ZHC jobs and workers and those in standard permanent jobs. Casual jobs and workers, on the other hand, look similar to their ZHC counterparts. Compared to permanent workers, ZHC workers report fewer (usual) hours worked (24.1 vs. 34.6 hours) and lower hourly pay (£9.81vs. £15.01 using the HOURPAY-based measure, $£ 9.15$ vs. $£ 10.04$ using the HRRATE-based measure). ${ }^{8}$ ZHCs (and casuals) are concentrated in the youngest age group (16-24), among students, single workers, migrants, black and other ethnic minority workers, among those with secondary education and those with low job tenure. ZHC (and casual) workers mostly describe themselves as part-time. ${ }^{9}$ The majority of $\mathrm{ZHCs}$ are also reported by their holders as permanent positions, despite the fact that they can, in practice, be severed at any time without notice. Approximately $50 \%$ of $\mathrm{ZHC}$ jobs are in personal service or elementary occupations (compared to $19 \%$ of

\footnotetext{
${ }^{7}$ The search retains all UK national newspaper articles that explicitly refer to "zero hours contracts".

${ }^{8}$ HOURPAY is a derived variable constructed by the ONS from earnings and hours variables which, although it has good coverage, is perceived to have a high degree of measurement error. HRRATE, because it is the response to a direct question about hourly pay, is perceived to be a more reliable measure, but at the cost of lower coverage (Ormerod and Ritchie, 2007).

${ }^{9}$ The LFS has no question on short-hours contracts (part-time jobs with a small number of guaranteed hours, where workers typically work additional non-guaranteed hours). Our assumption is that workers on such contracts will describe themselves as part-time but will not describe themselves as being on a ZHC.
} 
permanent jobs), with $43 \%$ found in two sectors, namely Distributions, Hotels and Restaurants and Other Services (compared to $24 \%$ for permanent jobs).

\section{INSERT TABLE 1}

To quantify the strength of the association of each of these characteristics with ZHCs, other (observable) things being equal, we turn to multivariate regression. Specifically, for all those in employment in the pooled 2017Q4 and 2018Q4 QLFS, we regress the probability of being on a $\mathrm{ZHC}$ on observable job and worker characteristics. The following probit model is estimated:

$$
\operatorname{Pr}\left(Z H C_{i}=1 \mid \boldsymbol{X}_{\boldsymbol{i}}\right)=\Phi\left(\boldsymbol{X}_{\boldsymbol{i}} \boldsymbol{\beta}^{\prime}\right)
$$

where $\mathrm{ZHC}_{\mathrm{i}}$ is a binary indicator taking value 1 if workers report to be on a $\mathrm{ZHC}$ and 0 otherwise, $\Phi$ is the cumulative distribution function of the standard normal distribution, and $\mathbf{X}_{\mathbf{i}}$ denotes the set of individual and job characteristics observed for worker $i$, including age groups, gender, marital status, ethnic group, migrant status, education level and study status, region of residence, indicators for the presence of children in the household, length of employment in months with the same employer, part-time, temporary job ${ }^{10}$ and private sector indicators, occupation and industry groups dummy variables and a dummy variable taking value 1 if workers were interviewed in 2018Q4 and 0 otherwise. Selected estimates - in the form of average marginal effects - are presented in Table 2.

\section{INSERT TABLE 2}

These estimates, when compared to an average ZHC prevalence of $2.8 \%$, highlight the concentration of ZHCs among particular worker groups. Workers in the 16-24 (65+) years age group are $1.02 \mathrm{pp}(1.59 \mathrm{pp})$ more likely to work on a ZHC compared to those in the $35-49$ years old age group, with full-time students $0.68 \mathrm{pp}$ more likely than others. Consistent with Koumenta \& Williams (2019), but in contrast to the raw associations in the data, employed women are less likely than employed men to hold a ZHC once other observable factors are held constant, by $0.24 \mathrm{pp}$, although this is not statistically significant at conventional levels. The probability of being on a ZHC is $1.40 \mathrm{pp}$ higher for black workers compared to whites. Workers with no educational qualifications are less likely to have a ZHC compared to all other education

\footnotetext{
${ }^{10}$ Temporary job $=1$ if the respondent answers the LFS question on whether their job is 'permanent' or 'temporary in some way' by selecting the latter, and 0 otherwise.
} 
levels. Part-time, temporary and private sector status all increase the probability of a ZHC, by 2.86pp, 4.29pp and 1.45pp respectively. Elementary occupation jobs (the excluded category) are more likely to be ZHCs compared to the other groups. There are further patterns by broad industry group, tenure and region, unreported here for conciseness, but available from the authors on request.

Because ONS reports on ZHCs only date back to 2013, with little in the way of detailed description of ZHC jobs and workers prior to that point, we know very little about whether, and if so how, the nature of $\mathrm{ZHC}$ jobs and $\mathrm{ZHC}$ workers have changed over time in the UK. In particular one might expect the characteristics of $\mathrm{ZHC}$ jobs and workers to be somewhat different now, following the apparently rapid growth in 2013 and subsequently, compared to the period before the rapid growth. Table 3 assesses the extent to which this is the case. Columns (1) and (2) present averages/proportions for selected worker and job characteristics for autumn/Q4 2001-2011 (before the rapid growth in reported ZHC numbers) and 2012-2018 (during and after the rapid growth in reported ZHC numbers). Columns (3) and (4) repeat this for non-ZHC jobs for comparative purposes.

\section{INSERT TABLE 3}

This exercise highlights several important compositional changes in ZHC jobs and workers. In particular, relative to non-ZHC workers, we see that ZHC jobs have become increasingly concentrated in the younger (16-24 years) age group, among full-time students, singles, migrants, black and other minority ethnic group workers, in the private sector, in personal service and elementary occupations, and in the distribution, accommodation and restaurant sector over time. This increasing concentration of ZHCs, despite their increased share of overall employment, is consistent with more marginal workers entering employment, and in particular ZHC employment, as employment rates have reached record highs in recent years. Table 3 also shows that hours and pay in ZHC jobs have fallen over time, with the average real hourly wage of ZHC workers lower in 2012-2018 than in 2001-2011 according to both LFS wage measures. The comparison with other forms of employment, for which real wages are little changed between the two periods, is stark (see also Figure 3). Note, however, that estimating a simple wage regression for these two periods pooled suggests that this relative decline is driven predominantly by the compositional changes presented elsewhere in Table 3, e.g. increased concentration at younger ages. A note of caution relating to the public awareness hypothesis is also appropriate here. If the growth in reported ZHCs was in part driven by increased public 
awareness rather than 'real' growth (as the analysis in Section 6 suggests), and if those previously under-reporting ZHCs were concentrated among 16-24s, full-time students and the other groups listed above, then we cannot rule out that at least some of this apparent compositional change in $\mathrm{ZHCs}$ could reflect these changing reporting attitudes.

\section{INSERT FIGURE 3}

\section{Where have the $\mathrm{ZHC}$ workers come from?}

To explore this question we exploit the LLFS over the period 2001-2018 to produce transition matrices for within-individual movements, over the course of one year, between labour market states and in particular into ZHCs.

The transition matrix presented in Table 4, similar to that presented by Datta et al. (2018), distinguishes flows from the following mutually exclusive labour market states: inactive; unemployed; employed with a full-time (non-ZHC) job; employed with a part-time (non-ZHC) job; self-employed (non-ZHC); and ZHC status. It is not possible to distinguish casual or other flexible/NGHCs in the LLFS as separate states, but Figure 4 uses the QLFS to show there is no clear 'smoking gun' in terms of proportions on such contracts that fall as ZHCs rise. The last column of Table 4 shows where ZHC workers come from in terms of prior labour market state (one year previously). (For inflows the raw counts rather than proportions are most informative.) The largest source of $\mathrm{ZHC}$ workers at time $\mathrm{t}+4$ is part-time non-ZHC workers at time $t$, followed by full-time workers at time t. That is not to say that ZHCs do not act as entrylevel (or re-entry) jobs, but taken together, just over half of those on a ZHC in any given year were in either full-time or part-time non-ZHC employment one year earlier. Datta et al. (2018) also note this pattern in the data. In the working paper version of this paper (Farina et al., 2019) we repeat this exercise separately for those with tenure with their current employer of less than / more than one year. We see flows from non-ZHC full-time and part-time employment into ZHCs both within and between employers. Perhaps surprising, however, is that three quarters of these flows are within employer. Most workers who report moving from a non-ZHC job to a ZHC job, are doing so with their existing employer.

\section{INSERT FIGURE 4 \& TABLE 4}

Whether this reclassification, particularly within job, reflects genuine change in employment contracts as opposed to changes in reporting of employment contracts driven by growing public 
awareness of ZHCs is, however, uncertain. We return to this question in Section 6. But before doing so we explore whether these transition patterns vary over the 2001-2018 period. Specifically, we generate separate transition matrices for 2001-2012 (before the period of most rapid growth), 2012-2015 (during the period of most rapid growth) and 2015-2018 (following the period of most rapid growth). ${ }^{11}$ These transition matrices show that 2012-15 does not stand out in terms of transition patterns, suggesting no particular transition or transitions are driven by the public awareness effect. Instead, transition patterns appear to evolve smoothly from the first period to the last period, with progressively higher movements into ZHCs from all origins, progressively higher ZHC persistence, and a steadily falling proportion of transitions into ZHCs that come from part-time and full-time employment.

\section{The Growth in Reported ZHC Prevalence}

Our final research question concerns the extent to which the growth in reported ZHC prevalence has been driven by increased awareness of ZHCs, which we proxy by national newspaper articles on and Google searches for ZHCs. Figure 5 presents the quarterly number of articles on ZHCs from UK national newspapers over the period 2001-2018, alongside the quarterly number of Google searches for the term 'zero hours contracts', in index form, for the period 2004-2018. Both figures suggest little public awareness of ZHCs prior to 2013, then dramatic jumps in awareness around the time that the number of reported ZHCs in the QLFS itself jumped. These correlations could reflect growing awareness / interest in ZHCs as a result of their growing prevalence. But they could also reflect growing reporting of ZHCs as a result of growing awareness of ZHCs among survey respondents and also potentially among employers. $^{12}$

\section{INSERT FIGURE 5}

To test this latter hypothesis we extend our earlier probit model (Equation 1) of workers' individual-level propensity to report ZHC contract status in the QLFS to include first the number of newspaper articles on ZHCs, and second the number of Google searches for 'zero hours contracts' as potential predictors of ZHCs. We estimate this extended model over the whole period 2001-2018, at biannual frequency, exploiting QLFS data for both Q2 and Q4 of

\footnotetext{
${ }^{11}$ Results available from the authors on request.

${ }^{12}$ In this case, an obvious follow-up question is what prompted the huge spikes in newspaper articles and Google searches in the second half of 2013. One conjecture, put forward by CIPD (2015), is that their own earlier (2013) report, which suggested considerably higher numbers of ZHCs than was previously thought to be the case, was the trigger.
} 
each year. In order to fit this data structure we aggregate our quarterly newspaper articles and Google search measures to biannual frequency (Q1-Q2, Q3-Q4 in each case). The specific hypothesis we therefore test is whether newspaper articles or Google searches in the previous two-quarter period predict reported ZHC status in the current two-quarter period.

The following probit model is estimated:

$$
\operatorname{Pr}\left(Z H C_{i, t}=1 \mid \boldsymbol{X}_{i, t}, N E W S_{t-1}\right)=\Phi\left(\boldsymbol{X}_{\boldsymbol{i}, t}^{\prime} \boldsymbol{\beta}+\gamma N E W S_{t-1}\right)
$$

$\mathrm{ZHC}_{\mathrm{i}, \mathrm{t}}$ is a binary indicator taking value 1 if worker $i$ surveyed at time $t$ reports a ZHC and 0 otherwise. $\mathrm{NEWS}_{\mathrm{t}-1}$ represents the number of newspaper articles (in hundreds) (or Google searches, in index form with the peak two-quarter period $=100$ ) on ZHCs for the preceding period. As before $\mathrm{X}_{\mathrm{i}, \mathrm{t}}$ includes controls for demographic and job characteristics, regional dummies, and now also seasonal dummies and a quadratic time trend. The assumption here is that lagging by one period and conditioning on $\mathrm{X}_{\mathrm{i}, \mathrm{t}}$ means we can treat $\mathrm{NEWS}_{\mathrm{t}-1}$ as exogenous. The trade-off is that lagging by one period, given the relatively low persistence of ZHCs at the individual level, means we may not pick up behavioural responses to growing coverage of ZHCs over shorter time periods. In an extension to (2) - designed to strengthen the interpretation of $\mathrm{NEWS}_{\mathrm{t}-1}$ as plausibly exogenous - we also include the lagged number of ZHCs as a further predictor. The additional trade-off in this case is that including lagged ZHCs, if there is a contemporaneous effect of NEWS, may soak up some of the causal effect we want to estimate. We therefore report both sets of estimates in Table 5.

\section{INSERT TABLE 5}

The results presented in columns 1 and 2 of Table 5 show that the number of newspaper articles on $\mathrm{ZHCs}$ has a positive and statistically significant effect on the probability of reporting being on a ZHC in the following period, whether lagged ZHCs are included or not. We draw a similar conclusion from the estimated effect of Google searches on reported ZHCs (columns 3 and 4). In other words we cannot reject the hypothesis that growing awareness of ZHCs contributed to the growth in reported ZHCs over the period 2001-2018. Further, the magnitude of these marginal effects is sufficiently large that, if we are prepared to interpret these estimates as something approaching causal, we can explain a substantial part of the rapid growth in reported ZHCs over 2013 and into 2014 as a response - either a reporting response or a real response on the part of employers - to growing awareness of ZHCs. Specifically, the estimates suggest that between one quarter and one third (newspaper articles) or between one half and two thirds 
(Google searches) of the 1.2pp growth in the prevalence of ZHCs over this period can be explained by increased awareness of ZHCs, with the smaller estimate in each case corresponding to the model including lagged ZHCs. ${ }^{13}$ This conclusion is robust to re-specifying the newspaper articles variable at the regional level including articles in local and regional newspapers in addition to national newspapers (results available from the authors on request), and to estimating (2) as a linear probability model (for the latter, including linear models disaggregating the public awareness effects over time, see Farina et al., 2019). To the extent that this reflects an awareness-induced reporting change rather than an awareness-induced contracting change on the part of employers, one implication is that the QLFS may indeed have substantially under-estimated the prevalence of ZHCs prior to 2013, as suggested (but not quantified) by the ONS (2014a) and others, and as suggested by the sectoral administrative data reported by Bessa et al. (2013) and Jacques (2013).

\section{Conclusions}

ZHCs generate intense debate, reflecting among other things the view that their use has risen dramatically in recent years, that they are concentrated among disadvantaged demographic groups, and that they are associated with disproportionately negative conditions for workers. Despite this, uncertainty has persisted about the prevalence, distribution and nature of ZHCs (and NGHCs more generally), and particularly about their growth over time. This paper addresses several important aspects of this uncertainty.

First, we argue that the headline ZHC count from the QLFS likely continues to underestimate the number of workers whose main job is a ZHC. Second, we show that ZHC jobs have become increasingly concentrated over time at younger ages, among students, migrants, black and minority ethnic workers, in the private sector, in personal service and elementary occupations, and in the distribution, accommodation and restaurant sector. Median real wages for ZHC jobs have also fallen over time relative to those for other jobs, although this mostly reflects changes in the composition of ZHC jobs and workers. Third, we show that many ZHC workers were previously employed in non-ZHC (particularly part-time) jobs, in many cases with the same

\footnotetext{
${ }^{13}$ The probability of reporting being on a ZHC (equivalent to the prevalence of ZHCs) increased from $0.84 \%$ in $2012 \mathrm{Q} 3 / 4$ to $2.04 \%$ in $2014 \mathrm{Q} 1 / 2$, an increase of $1.2 \mathrm{pp}$. The two-quarter number of newspaper articles on ZHCs increased from 18 in 2012Q1/2 to 1026 in 2013Q3/4, an increase of 1008 (or 10.08 given the variable is expressed in hundreds). The Google search index increased from 11 in 2012Q1/2 to 81 in 2013Q3/4, an increase of 70. Multiplying the estimated marginal effects by the increases in the relevant predictor variables gives the predicted change in the probability of reporting a ZHC over the relevant period.
} 
employer, rather than being new or re-entrants to employment. This reclassification within job matches could be 'real' (i.e. it could genuinely reflect changing contractual arrangements, suggesting growing insecurity at the individual as well as the aggregate level in this part of the labour market), it could reflect increased reporting of ZHCs driven by increased awareness of ZHCs among LFS respondents, or it could reflect some combination of the two. Finally, we show that growth in public awareness contributed to the growth in reported ZHCs over this period, with our estimates suggesting in particular that it can explain between one quarter and two thirds of the observed rapid growth in ZHCs over the period 2013/14.

Efforts to improve our understanding of ZHCs are particularly timely given the range of policy interventions, from banning ZHCs to imposing a wage premium on non-guaranteed hours to imposing a right-to-convert for workers, currently being proposed in the mainstream of the UK debate (e.g. see Taylor et al., 2018). We do not directly address these policy proposals here, but the similarity between $\mathrm{ZHCs}$ and casual jobs raises the question as to whether banning ZHCs might simply displace workers into other forms of NGHC jobs. Similarly, would banning NGHC jobs more broadly displace workers onto (potentially very) short-hours contracts or even destroy some jobs concentrated among disadvantaged groups of workers? Imposing a minimum wage premium on non-guaranteed hours could avoid such 'change in name only' displacement effects, but perhaps with uncertain employment effects again concentrated among disadvantaged groups. Indeed, if minimum wage increases more generally have been leading to increased use of ZHCs, as suggested by Datta et al. (2018), then would making this employer response option more costly increase the likelihood of negative employment or hours impacts of future minimum wage increases? Finally, a right to convert could improve worker options, and could potentially help to change expectations on both sides of the labour market, even if lack of employment protection for ZHC workers mean such rights could perhaps be circumvented by some employers in practice.

In assessing the quality of available data on ZHCs in the UK, this paper also raises the question of whether such data might plausibly be improved looking forward. For the LFS, consideration could be given to including the question on ZHCs in Q1 and Q3; to rewording FLEX10 to reduce the risk that those workers on ZHCs whose hours tend to be regular are overlooked; to including an additional question on whether respondents have employment contracts that do not guarantee any hours, and if so of what type; to including a question on contract type in relation to second jobs; and even to the introduction of a special module on the adoption of atypical contractual forms. Collecting information on ZHCs and other contractual forms from 
employers in the Annual Survey of Hours and Earnings could help to fill the gap left by the discontinued ONS Business Survey. (Re-)introducing the BHPS question on ZHCs into Understanding Society, now ZHCs are much more widely reported than prior to 2009, would enable longitudinal analysis beyond the five quarters offered by the LLFS. Of course none of these options are costless. 


\section{References}

Adams, A. and Prassl, J. (2018). Zero-Hours Work in the United Kingdom. Geneva: International Labour Organization.

Bessa, I., Forde, C., Moore, S., and Stuart, M. (2013). The National Minimum Wage, earnings and hours in the domiciliary care sector. University of Leeds and Low Pay Commission, London .

Brinkley, I. (2013). Flexibility or insecurity? Exploring the rise in zero hours contracts. The Work Foundation, Lancaster University.

Buddelmeyer, H. and Wooden, M. (2011). Transitions out of casual employment: the Australian experience. Industrial Relations, 50, 109-130.

Carroll, CD. (2003). Macroeconomic Expectations of Households and Professional Forecasters. Quarterly Journal of Economics, 118(1), 269-298.

CIPD (2013). Zero-hours contracts: Myth and reality. London: Chartered Institute of Personnel and Development.

CIPD (2015). Zero hours and short hours contracts in the UK: employer and employee perspectives. London: Chartered Institute of Personnel and Development.

Datta, N., Giupponi. G. and Machin, S. (2018). Zero Hours Contracts and Labour Market Policy. Paper for Economic Policy 68th Panel Meeting, 4-5 October 2018, Vienna.

DBIS (2013). Zero hours contracts: consultation. London: Department for Business, Innovation and Skills.

Farina, E., Green, C. and McVicar, D. (2019). Zero hours contracts and their growth. IZA Discussion Paper 12291, IZA, Bonn. 
Jacques, H. (2013). What do zero hours contracts mean for doctors? British Medical Journal BMJ 2013; 346:F3610.

Katz, LF. and Krueger, AB. (2016). The Rise and Nature of Alternative Work Arrangements in the United States, 1995-2015.NBER Working Paper No. 22667.

Koumenta, M. and Williams, M. (2019). An anatomy of zero hours contracts in the UK. Industrial Relations Journal, 50(1), 20-40.

Lamla, M. and Lein, S. (2008), The Role of Media for Consumers' Inflation Expectation Formation, KOF Working Papers 201, KOF Swiss Economic Institute.

Lass, I. and Wooden, M. (2019). The Structure of the Wage Gap for Temporary Workers: Evidence from Australian Panel Data. British Journal of Industrial Relations (forthcoming).

Lucas, R. (1997). Youth, gender and part-time work - students in the labour process. Work, Employment \& Society 11(4): 595-614.

McVicar, D. (2017). Zero Hours Contracts, Job Quality and Impacts on Workers. NI Assembly KESS Briefing 25/01/2017.

Murphy, R. (2017). Call My Rep! How Unions Overcame the Free-Rider Problem. CESifo Working Paper Series No. 6362.

ONS (2014a). Labour Force Survey estimates of people in employment reporting a zero hours contract, methodological note, August 2014.

ONS (2014b). Guidance Note: Contracts that do not guarantee a minimum number of hours, 24 June 2014.

ONS (2016). Contracts that do not guarantee a minimum number of hours: September 2016.

ONS (2017). Labour Force Survey: zero-hours contracts data tables: March 2017. 
ONS (2018). Contracts that do not guarantee a minimum number of hours: April 2018.

Ormerod, C. and Ritchie, F. (2007). Issues in the measurement of low pay. Economic and Labour Market Review, 1(6), 37-45.

O’Sullivan M., Turner T., McMahon J., Ryan L., Lavelle J., Murphy C., O’Brien M. and Gunnigle, P. (2015). A Study on the Prevalence of Zero Hours Contracts among Irish Employers and their Impact on Employees. University of Limerick.

Pennycook, M., Cory, G. and Alakeson, V. (2013). A matter of time: the rise of zero-hours contracts. London: Resolution Foundation.

Prosser, T. (2016). Dualization or liberalization? Investigating precarious work in eight European countries. Work, Employment \& Society, 30, 949-965.

Taylor, M., Marsh, G., Nicole, D. and Broadbent, P. (2017). Good Work: The Taylor Review of Modern Working Practices. Available at:

https://www.gov.uk/government/publications/good-work-the-taylor-review-of-modernworking-practices (last accessed 7 March 2019).

van der Wiel, K. (2009). Have You Heard the News? How Real-Life Expectations React to Publicity, IZA Discussion Papers, 4064, Institute for the Study of Labor. 
Figure 1: People (Thousands) in Employment on ZHCs (in Their Main Job)

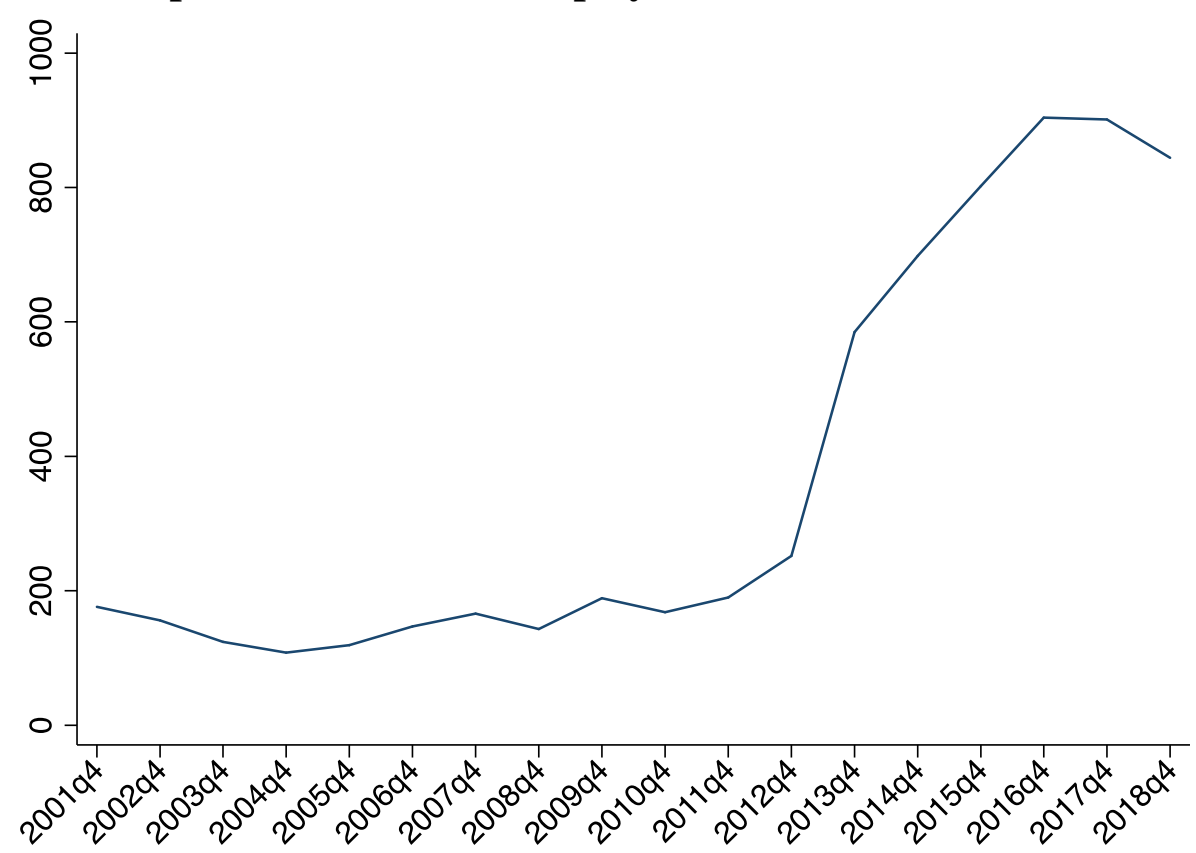

Source: QLFS 2001-2018, Q4 data only. 


\section{Figure 2: Estimated Impact of the Q2 Shiftwork Check on ZHC Prevalence}

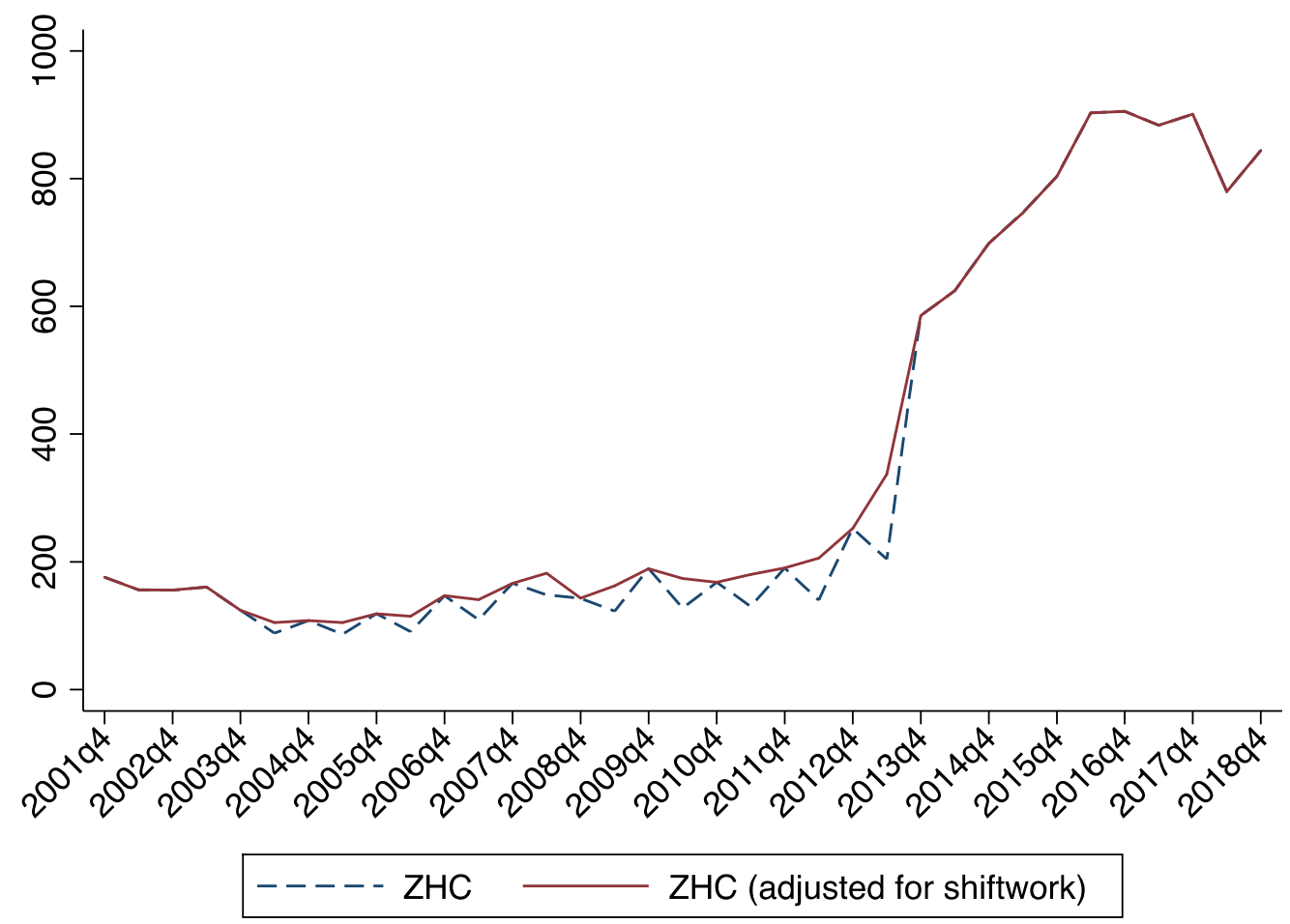

Note: The figure reports the number (in thousands) of people in employment on ZHCs for Q2/Q4 of each year from 2001-2018, obtained using the QLFS. The estimates represented by the dashed line reflect the presence of the shiftwork check in Q2 during the period 2004-2013. The solid line presents an adjustment, including the authors' estimate of the number of people on shift-work potentially on ZHCs. 
Figure 3: Evolution of real median hourly wages - ZHC vs Non-ZHC workers (20012018)

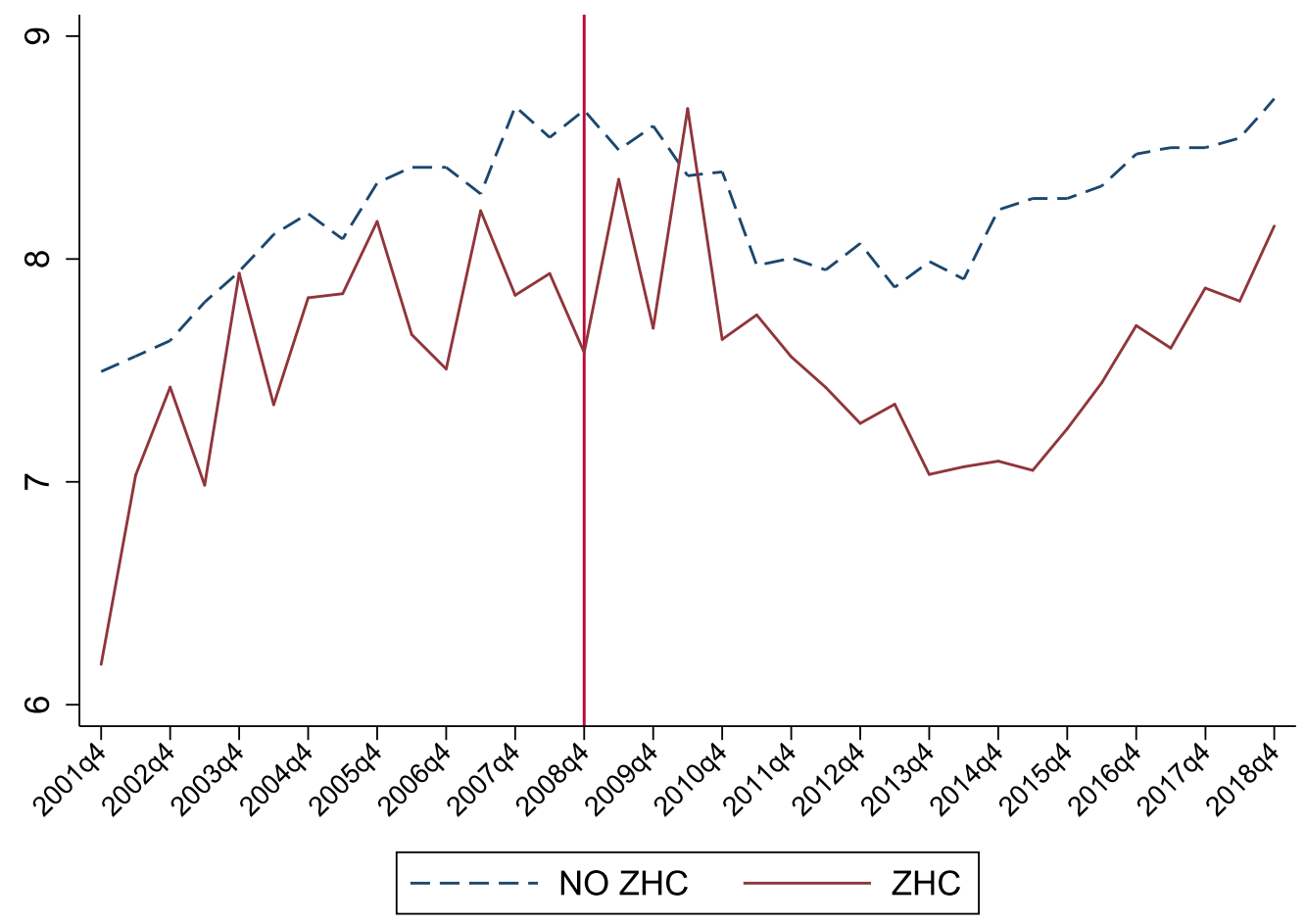

Note: Authors’ calculations using QLFS Q2/Q4 2001-2018 (HRRATE). Wages are expressed in £2017. 
Figure 4: Flexible Employment Types (Proportion of Those Employed)

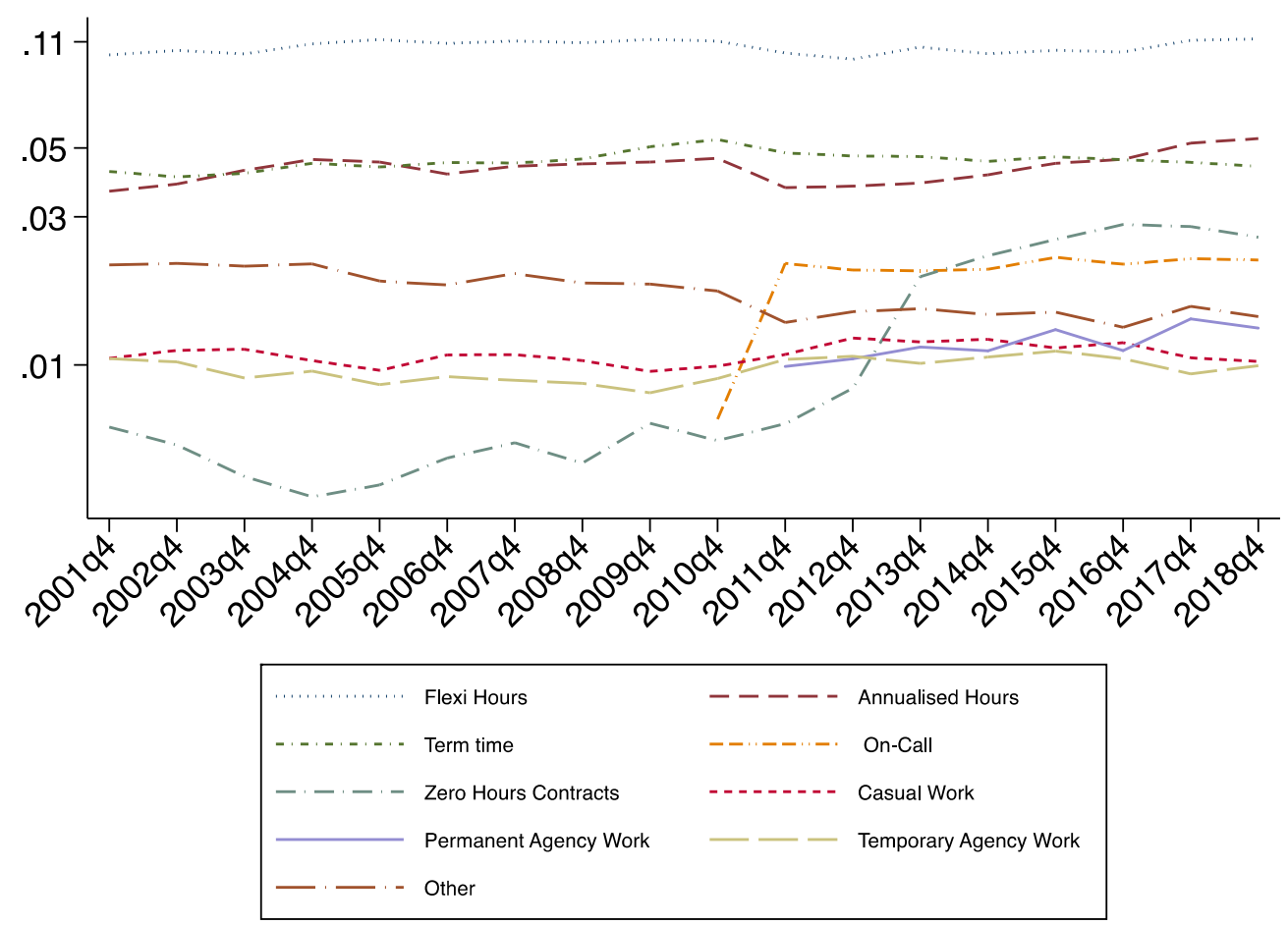

Note: On Call and Permanent Agency were only added as options from 2010 and 2011 respectively. 
Figure 5: UK National Newspaper Articles and Google Searches on ZHCs

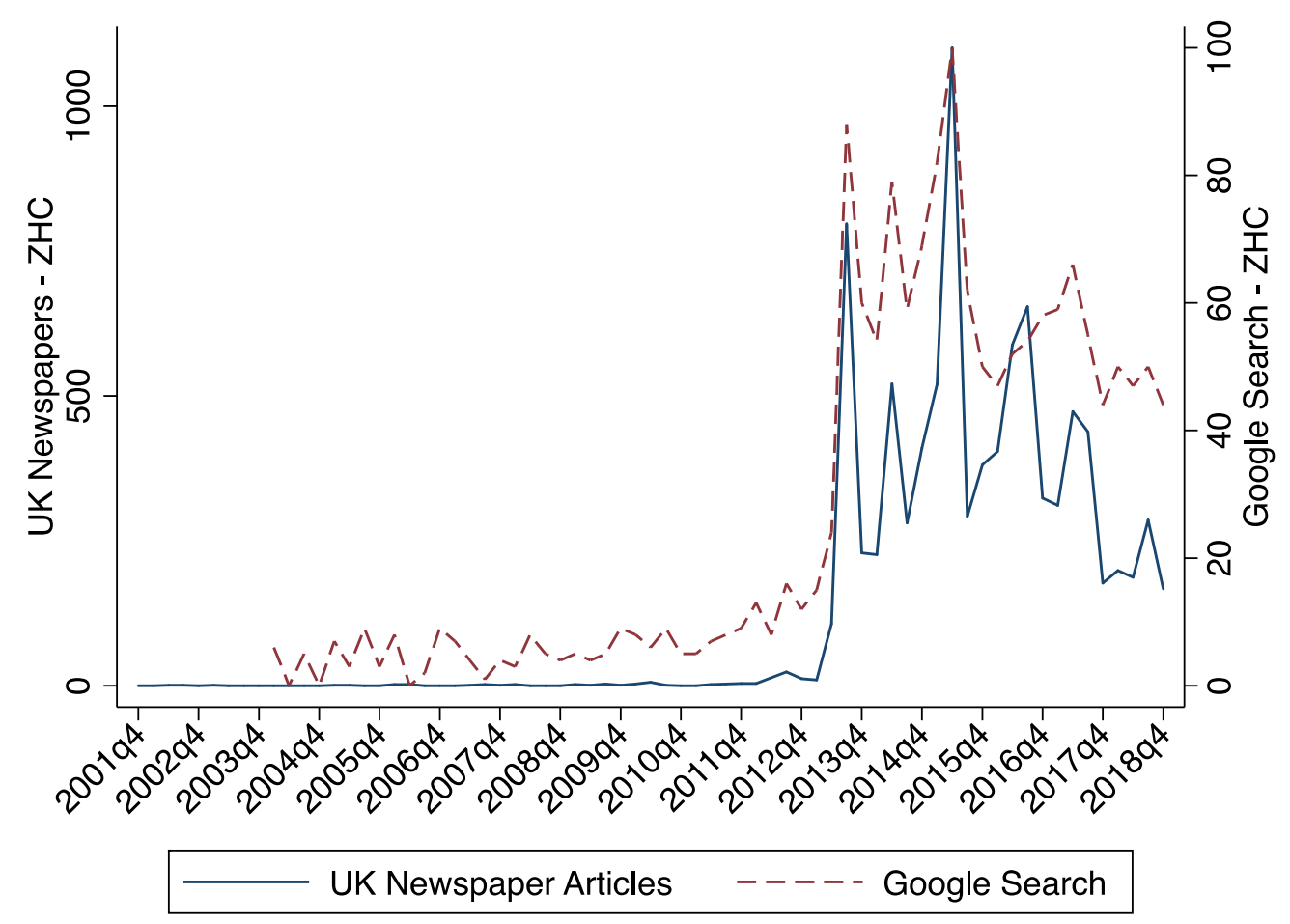

Source: Authors' calculations using Lexis-Nexis and Google Trends. 
Table 1: Descriptive Statistics by Employment Contract Type

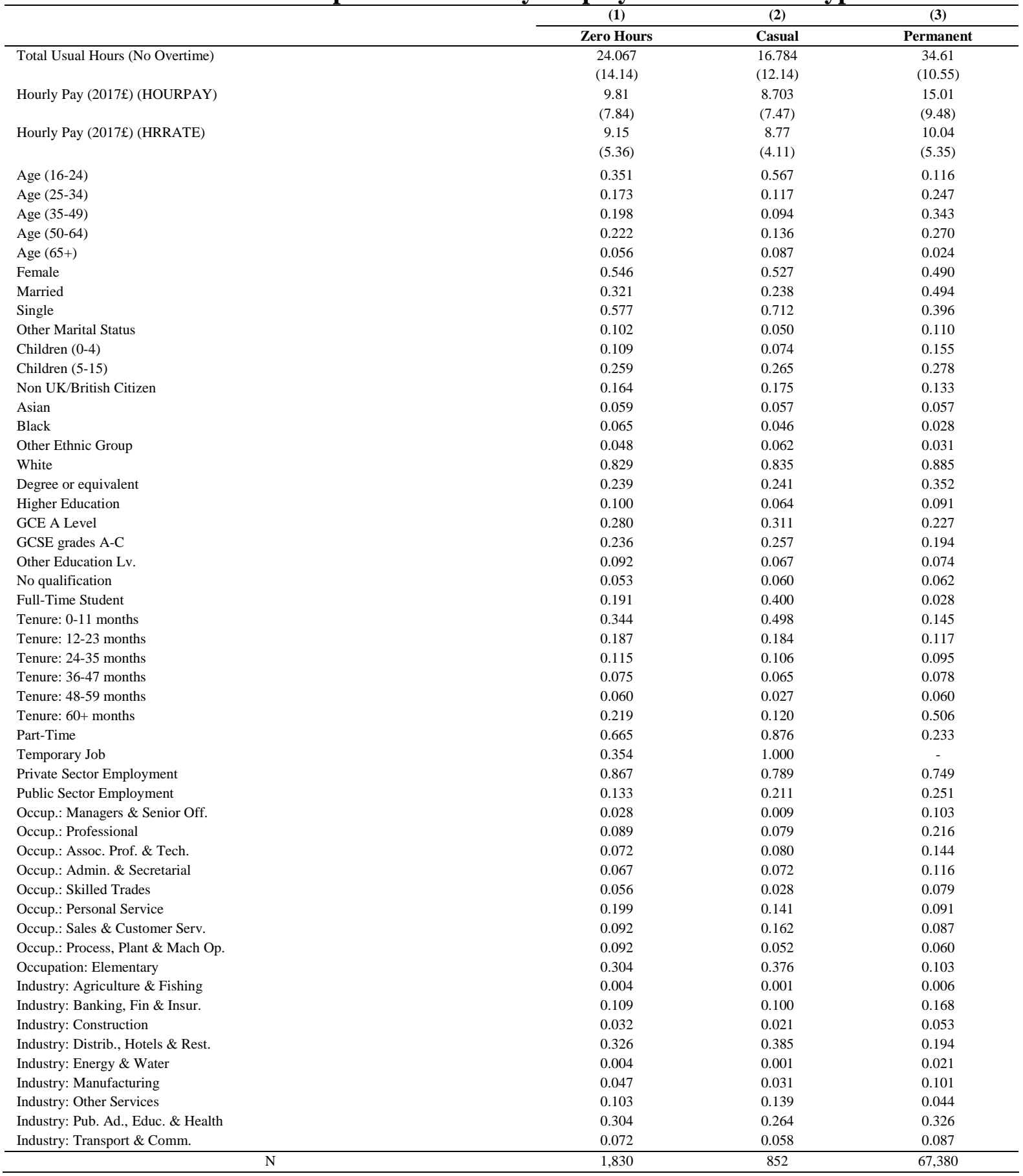

Note: Entries report weighted means / proportions (standard deviations in parentheses) for workers in ZHC jobs (column 1), casual jobs (column 2), and non-ZHC permanent jobs (column 3), averaged over the period 2017-2018, using QLFSQ4 data. We permit the ZHC and casual categories to overlap. 
Table 2: Predictors of ZHCs, Probit Model Average Marginal Effects

\begin{tabular}{|c|c|c|c|}
\hline & $\begin{array}{l}\text { A.M.E } \\
\text { (st. error) }\end{array}$ & & $\begin{array}{l}\text { A.M.E } \\
\text { (st. error) }\end{array}$ \\
\hline \multirow[t]{2}{*}{ Age (16-24) } & $0.0102 * * *$ & Other Education & $0.0097 * * *$ \\
\hline & $(0.0024)$ & & $(\mathbf{0 . 0 0 3 3})$ \\
\hline \multirow[t]{2}{*}{ Age $(25-34)$} & 0.0004 & Full-Time Student & $0.0068 * * *$ \\
\hline & $(0.0020)$ & & $(0.0025)$ \\
\hline \multirow[t]{2}{*}{ Age (50-64) } & $0.0056 * * *$ & Part-Time & $0.0286 * * *$ \\
\hline & $(0.0020)$ & & $(0.0016)$ \\
\hline \multirow[t]{2}{*}{ Age $(65+)$} & $0.0159 * * *$ & Temporary Job & $0.0429 * * *$ \\
\hline & $(\mathbf{0 . 0 0 3 2})$ & & $(0.0018)$ \\
\hline \multirow[t]{2}{*}{ Female } & -0.0024 & Private Sector Employment & $0.0145 * * *$ \\
\hline & $(0.0015)$ & & $(0.0019)$ \\
\hline \multirow[t]{2}{*}{ Single } & $0.0055 * * *$ & Occ: Managers \& Senior Off. & $-0.0306 * * *$ \\
\hline & $(0.0017)$ & & $(0.0038)$ \\
\hline \multirow[t]{2}{*}{ Other Marital Status } & 0.0024 & Occ: Professional & $-0.0279 * * *$ \\
\hline & $(0.0020)$ & & $(0.0027)$ \\
\hline \multirow[t]{2}{*}{ Children (0-4) } & -0.0024 & Occ.: Associate Prof. \& Tech. & $-0.0280 * * *$ \\
\hline & $(0.0020)$ & & $(0.0028)$ \\
\hline \multirow[t]{2}{*}{ Children (5-15) } & $-0.0028 *$ & Occ: Admin. \& Secretarial & $-0.0254 * * *$ \\
\hline & $(0.0016)$ & & $(0.0026)$ \\
\hline \multirow[t]{2}{*}{ Non UK/British Citizen } & 0.0027 & Occ: Skilled Trades & $-0.0147 * * *$ \\
\hline & $(0.0018)$ & & $(0.0030)$ \\
\hline \multirow[t]{2}{*}{ Asian } & -0.0010 & Occ: Personal Service & -0.0023 \\
\hline & $(0.0031)$ & & $(0.0022)$ \\
\hline \multirow[t]{2}{*}{ Black } & $0.0140 * * *$ & Occ: Sales \& Customer Serv. & $-0.0288 * * *$ \\
\hline & $(0.0032)$ & & $(0.0025)$ \\
\hline \multirow[t]{2}{*}{ Other Ethnic Groups } & $0.0086 * * *$ & Occ: Process, Plant \& Machine Op. & 0.0028 \\
\hline & $(\mathbf{0 . 0 0 3 3 )}$ & & $(0.0026)$ \\
\hline \multirow[t]{2}{*}{ Degree or equivalent } & $0.0104 * * *$ & D.2018Q4 (=1) & -0.0013 \\
\hline & $(0.0032)$ & & $(0.0012)$ \\
\hline \multirow[t]{2}{*}{ Higher Education } & $0.0165 * * *$ & & \\
\hline & $(\mathbf{0 . 0 0 3 3 )}$ & & \\
\hline \multirow[t]{2}{*}{ GCE A Level } & $0.0098 * * *$ & & \\
\hline & $(0.0029)$ & & \\
\hline \multirow[t]{2}{*}{ GCSE grades A-C } & $0.0092 * * *$ & & \\
\hline & $(0.0029)$ & & \\
\hline \multicolumn{3}{|l|}{$\mathrm{N}$} & 58,366 \\
\hline \multicolumn{3}{|l|}{ Pseudo- $\mathrm{R}^{2}$} & 0.250 \\
\hline \multicolumn{4}{|c|}{$\begin{array}{l}\text { Notes: Significance at the } 10 \% \text { level is represented by } * \text {, at the } 5 \% \text { level by } * * \text {, and at the } 1 \% \text { level by } * * * \text { Each entry reports the average } \\
\text { marginal effects and robust standard errors (in parentheses) obtained regressing a binary indicator taking value } 1 \text { if individual } i \text { reports to work } \\
\text { on a ZHC and } 0 \text { otherwise on worker and job characteristics, pooling those in employment in the QLFS for } 2017 \mathrm{Q} 4 \text { and } 2018 \mathrm{Q} 4 \text {. Tenure } \\
\text { categories and sectoral dummies as in Table } 1 \text {, along with Government Office Region dummies, are included in the model but not reported. } \\
\text { For each set of binary indicators the excluded categories are as follows: age group } 35-49 \text {, male, married, families with no children in the age } \\
\text { group } 0-4 \text { or 5-15, white, no qualifications, duration of tenure with the same employer below } 13 \text { months, full-time work, permanent job, public } \\
\text { sector employment, elementary occupations, and finally, agriculture and fishing. }\end{array}$} \\
\hline
\end{tabular}


Table 3: Descriptive Statistics - ZHC Job and Worker Characteristics over Time

\begin{tabular}{|c|c|c|c|c|}
\hline & \multicolumn{2}{|c|}{$\mathrm{ZHC}$} & \multicolumn{2}{|c|}{ NON ZHC } \\
\hline & 2001-2011 & 2012-2018 & 2001-2011 & 2012-2018 \\
\hline \multirow[t]{2}{*}{ Total Usual Hours (No Overtime) } & 25.533 & $23.912 * * *$ & 34.086 & $34.016 * *$ \\
\hline & (15.63) & $(14.33)$ & (12.62) & $(12.41)$ \\
\hline \multirow[t]{2}{*}{ Hourly Pay (2017£) - HOURPAY } & 12.02 & $9.12 * * *$ & 14.26 & $14.47 * * *$ \\
\hline & (10.94) & (7.57) & $(9.51)$ & (9.45) \\
\hline \multirow[t]{2}{*}{ Hourly Pay (2017£) - HRRATE } & 9.42 & $8.57 * * *$ & 10.27 & 10.04 \\
\hline & (5.89) & $(4.52)$ & $(21.12)$ & (13.14) \\
\hline Age (16-24) & 0.252 & $0.312 * * *$ & 0.118 & $0.092 * * *$ \\
\hline Age (25-34) & 0.163 & 0.167 & 0.198 & $0.193 * * *$ \\
\hline Age (35-49) & 0.278 & $0.215^{* * * *}$ & 0.389 & $0.362 * * *$ \\
\hline Age (50-64) & 0.251 & 0.239 & 0.268 & $0.307 * * *$ \\
\hline Age (65+) & 0.056 & $0.067 *$ & 0.027 & $0.046 * * *$ \\
\hline Female & 0.531 & $0.559 * *$ & 0.480 & $0.487 * * *$ \\
\hline Married & 0.477 & $0.361^{* * * *}$ & 0.566 & $\mathbf{0 . 5 5 0} * * *$ \\
\hline Single & 0.402 & $0.516 * * *$ & 0.309 & $0.323 * * *$ \\
\hline Other Marital Status & 0.121 & 0.123 & 0.125 & $0.127 * * *$ \\
\hline Children (0-4) & 0.118 & 0.115 & 0.137 & $0.148 * * *$ \\
\hline Children (5-15) & 0.262 & 0.261 & 0.293 & $0.282 * * *$ \\
\hline Non UK/British Citizen & 0.083 & $0.148 * * *$ & 0.088 & $0.121 * * *$ \\
\hline Asian & 0.036 & $0.048 * *$ & 0.034 & $0.047 * * *$ \\
\hline Black & 0.015 & $0.05 * * *$ & 0.016 & $0.021 * * *$ \\
\hline Other Ethnic Group & 0.021 & $0.033 * * *$ & 0.019 & $0.025 * * *$ \\
\hline White & 0.928 & $0.869 * * *$ & 0.932 & $0.906 * * *$ \\
\hline Degree or equivalent & 0.202 & 0.210 & 0.223 & $0.323 * * *$ \\
\hline Higher Education & 0.113 & $0.101 *$ & 0.101 & 0.101 \\
\hline GCE A Level & 0.268 & 0.274 & 0.241 & $0.229 * * *$ \\
\hline GCSE grades A-C & 0.234 & $0.255^{* *}$ & 0.220 & $0.198 * * *$ \\
\hline Other Education Lv. & 0.113 & 0.101 & 0.118 & $0.081 * * *$ \\
\hline No qualification & 0.069 & $0.058 * *$ & 0.098 & $0.068 * * *$ \\
\hline Full-Time Student & 0.146 & $0.179 * * *$ & 0.036 & $0.028 * * *$ \\
\hline Part-Time & 0.605 & $0.665 * * *$ & 0.271 & $0.277 * * *$ \\
\hline Temporary Job & 0.306 & $0.352 * * *$ & 0.058 & $0.054 * * *$ \\
\hline Private Sector & 0.802 & $0.852 * * *$ & 0.749 & $0.763 * * *$ \\
\hline Occup.: Managers \& Senior Officials & 0.081 & $0.021 * * *$ & 0.145 & $0.109 * * *$ \\
\hline Occup.: 'Professional & 0.099 & 0.087 & 0.135 & $0.207 * * *$ \\
\hline Occup.: 'Associate Prof. \& Tech. & 0.111 & $0.07 * * *$ & 0.140 & 0.139 \\
\hline Occup.: Admin. \& Secretarial & 0.088 & $\mathbf{0 . 0 5 9} * * *$ & 0.124 & $0.111 * * *$ \\
\hline Occup.: Skilled Trades & 0.082 & $0.051 * * *$ & 0.111 & $0.106 * * *$ \\
\hline Occup.: Personal Service & 0.163 & $0.233 * * *$ & 0.082 & $0.091 * * *$ \\
\hline Occup.: Sales \& Customer Serv. & 0.109 & $0.085 * * *$ & 0.076 & $0.075 * *$ \\
\hline Occup.: Process, Plant \& Machine Op. & 0.069 & $0.086 * *$ & 0.073 & $0.063 * * *$ \\
\hline Occup.: Elementary & 0.198 & $0.308 * * *$ & 0.114 & $0.10 * * *$ \\
\hline Industry: Distrib., Hotels \& Rest. & 0.259 & $0.298 * * *$ & 0.189 & $0.176 * * *$ \\
\hline $\mathrm{N}$ & 2,451 & 5,602 & 464,570 & 255,475 \\
\hline
\end{tabular}

Notes: Significance at the $10 \%$ level is represented by $*$, at the $5 \%$ level by **, and at the $1 \%$ level by ***. Each entry in Columns (1) and (3) report the (unweighted) means/proportions and standard deviations (in parentheses) for ZHC (non-ZHC) job and worker characteristics respectively, averaged over the period 2001Q4-2011Q4. Each entry in Columns (2) and (4) report the equivalent statistics for 2012Q4-2018Q4 Statistically significant differences in means between (1) and (2) and between (3) and (4) are in bold font. 
Table 4: Transition Matrix - 2001-2018

\begin{tabular}{lcccccc}
\hline \multirow{2}{*}{$\begin{array}{c}\text { Status } \\
\text { at t }\end{array}$} & Inactive & Unemp. & Full-time & Part-time & $\begin{array}{c}\text { Self- } \\
\text { employed }\end{array}$ & ZHC \\
\cline { 2 - 6 } & 88.54 & 2.95 & 1.81 & 5.23 & 1.26 & 0.21 \\
Inactive & $(62,730)$ & $(2,089)$ & $(1,281)$ & $(3,709)$ & $(893)$ & $(150)$ \\
Unemployed & 22.78 & 33.41 & 21.61 & 16.11 & 4.88 & 1.21 \\
Full-time & $(1,411)$ & $(2,069)$ & $(1,338)$ & $(998)$ & $(302)$ & $(75)$ \\
Part-time & 2.79 & 1.48 & 89.44 & 4.44 & 1.59 & 0.26 \\
& $(2,434)$ & $(1,294)$ & $(78,115)$ & $(3,877)$ & $(1,391)$ & $(225)$ \\
Self-employed & 8.56 & 1.65 & 9.11 & 77.95 & 1.72 & 1.02 \\
& $(2,980)$ & $(575)$ & $(3,170)$ & $(27,137)$ & $(599)$ & $(354)$ \\
ZHC & 5.07 & 0.91 & 6.01 & 2.75 & 84.65 & 0.63 \\
& $(976)$ & $(175)$ & $(1,157)$ & $(529)$ & $(16,309)$ & $(121)$ \\
& 11.44 & 2.93 & 21.94 & 26.86 & 11.30 & 25.53
\end{tabular}

Notes: Each entry reports the percentage (number) of workers at time t distributed according to their economic activity status at time $t+4$ (four quarters / one year later). The figures were obtained using the LLFS cohorts starting in spring/Q2 and autumn/Q4 of each year over the period 2001-2018 
Table 5: The Impact of Public Awareness on ZHCs, Probit Model, Average Marginal Effects

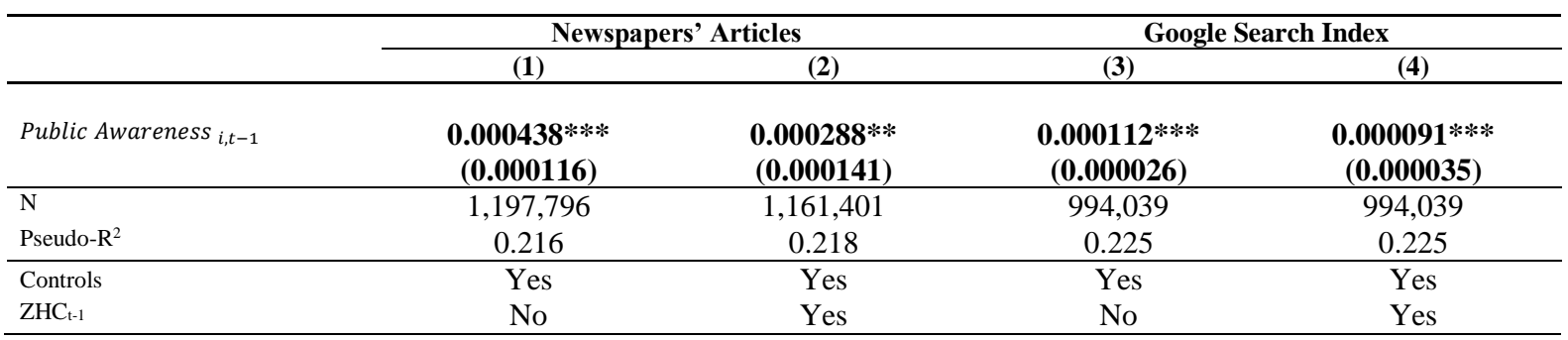

Significance at the $10 \%$ level is represented by ${ }^{*}$, at the $5 \%$ level by ${ }^{* *}$, and at the $1 \%$ level by ${ }^{* * *}$. Each entry reports the average marginal effect and associated standard error (in parentheses) for the variable of interest. The dependent variable takes value 1 if workers report to be on ZHC and 0 otherwise. Controls include demographic indicators (gender, age group, marital, migrant and study status, ethnic group, highest educational qualification achieved, and indicators for the presence of children in the household), job characteristics (temporary job, part-time job, public sector job, occupation and industry indicators), a quadratic time trend, a seasonal dummy (=1 if LFS respondents are interviewed in Q4 and 0 otherwise), regional dummies and the shift-work block dummy. Results in Columns 1 and 2 are obtained using the number of UK newspapers' articles (/100) on ZHCs as a measure of public awareness. Columns 3 and 4 use the Google Search Index as a measure for public awareness. Standard errors are clustered at the two-quarter level. 